Journal Home Page:
http://perlinguam.journals.ac.za

\title{
TEACHING LEXICOGRAPHY AT A SOUTH AFRICAN UNIVERSITY
}

\author{
Dion Nkomo \\ Rhodes University
}

\begin{abstract}
Following South Africa's democratic constitution, lexicography was identified as an important practice that would play an enormous role in the implementation of the country's multilingual language policy. National Lexicography Units (NLUs) were established for each of the eleven official languages, including reconstituting the dictionary projects that existed for languages such as Afrikaans, English and isiXhosa. This consolidated the position of lexicography as an academic area of study at a number of South African universities. The African Language Studies Section of the School of Languages at Rhodes University introduced lexicography at Honours level in 2010. The present article reflects on the curriculum development processes associated with the teaching of lexicography at this particular university. It demonstrates how the knowledge that constitutes lexicography is pedagogised to develop courses that respond to the South African context.
\end{abstract}

\section{INTRODUCTION}

This article reflects on curriculum issues in the teaching of lexicography in the African Language Studies Section of the School of Languages at Rhodes University. An effort is made to demonstrate how theoretical underpinnings of curriculum studies have guided the development of the relevant curricula. The notions of curriculum responsiveness and learning outcomes are vital in the discussion, highlighting how the relevant curricula have been developed in ways that hope to maximise learning opportunities for students. To achieve this, the article makes use of material from the curriculum documents, citing statements concerning required prior learning for the students; specific outcomes; knowledge areas covered by the respective courses; and the overall aims of teaching lexicography at this particular university. The aim of the article is to demonstrate how teaching lexicography can play a complementary role with dictionary research in order to improve lexicographic practice and dictionary culture in a multilingual South Africa.

\section{CURRICULUM ORIENTATIONS AND CURRICULUM RESPONSIVENESS}

Any discussion of curriculum development should be informed by a clear understanding of curriculum. Yet the meaning of curriculum remains contentious (cf. Smith, 2000; Knight, 2001). Smith (2000: 1) states that curriculum literally refers to a course. The Rhodes University Policy on Curriculum Development and Review (henceforth the Rhodes Policy) also alludes to this sense. It states that the term 'is generally used to refer to the syllabus - the list of subjects, topics and the text included in a course of study'. This sense is, however, not all-encompassing of the different aspects of curriculum such as curriculum orientations and 
factors that influence curriculum design, decisions and practice. As Knight (2001: 369) argues, 'curriculum is more than just content'.

In order to enhance an understanding of curriculum theory and practice, more comprehensive definitions of the concept have been formulated. One such example is the definition that was formulated by John Kerr and adopted by Smith (2000). This definition regards curriculum as '[a]1l learning which is planned and guided by the school, whether it is carried on in groups or individually, inside or outside the school' (Smith, 2000: 1-2). Extending the meaning of curriculum over and above content, Knight (2001 369) considers it as 'a set of purposeful, intended experiences' which include 'content, organisation, learning and teaching methods, and assessment'. In terms of the Rhodes Policy, curriculum 'incorporates subject content and skills, the manner of teaching and assessment that is followed, the philosophical outlook of the teacher and the learners'. Besides being more than just content, another fundamental aspect of curriculum is that it is 'planned and guided' learning and teaching. The Rhodes Policy regards it as 'both the planned process, the actual implementation of the teaching and the students" "experiences" of the learning process'. Accordingly, this article considers how content and teaching are planned and how the plans are implemented in the teaching of lexicography at Rhodes University.

Depending on how one interprets curriculum, at least four curriculum orientations or approaches may be identified. According to Smith (2000: 2), these are:

- $\quad$ Curriculum as a body of knowledge to be transmitted

- Curriculum as an attempt to achieve certain ends in students - product

- $\quad$ Curriculum as process

- Curriculum as praxis

The first approach restricts the meaning of the term to subject content. It is consistent with the transmission perspective of teaching and learning whereby students are regarded as empty vessels which have to be filled with knowledge by the teacher, with knowledge itself being regarded as discreet entities that can be fixed within texts and the brain. Such a perspective is, therefore, far too limited as an explanation of the orientations that explain the curriculum decisions discussed in this article.

The second sense results from the various socio-economic and political factors which have influenced the management of higher education in different parts of the world, including South Africa (Toohey, 1999; Smith, 2000; Boughey, 2004; Cross, Mungadi \& Rouhani, 2002). Through this orientation, Smith (2000: 4) states that '[o]bjectives are set, a plan is drawn up, then applied, and the outcomes (products) measured'. As a product, curriculum is marketed to students who are themselves treated as marketable products in the labour market. This approach is useful in understanding the notion of curriculum responsiveness, which informs decision making in curriculum design. However, it is also lacking with regard to insights about the meaning-making processes that are central to education.

Against the background of the criticism of the syllabus and product approaches, the process orientation to curriculum provides an alternative which enhances an understanding of "what 
actually happens in the classroom and what people do to prepare and evaluate' (Smith, 2000: 9). According to the Imaginative Curriculum Network, it places 'more emphasis on the individual needs of the student', going further to consider how to best help students achieve educational goals. Smith (2000: 9-10) outlines the process as follows:

Teachers enter a particular schooling and situation with an understanding of their role and expectations others have of them, and a proposal for action which sets out essential principles and features of the educational encounter. Guided by these, they encourage conversations between, and with, people in the situation out of which may come thinking and action. They continually evaluate the process and what they can see of outcomes.

The role of informed planning and action by the teacher, the dialogical nature of teaching and learning between teachers and students, as well as the importance of evaluation which informs further planning and practice, are vital. Although this approach is considered progressive by the Imaginative Curriculum Network, Smith (2000: 11) argues that it is driven by general principles, thereby distinguishing itself from the praxis model. Compared to the former, in the praxis approach:

Teachers enter particular schooling and situations with a personal, but shared idea of the good and commitment to human emancipation ... they encourage conversations between, and with, people in the situation out of which may come informed and committed action. ... the curriculum develops through the dynamic interaction of action and reflection. (Smith, 2000: 11-12)

The praxis orientation 'makes explicit commitment to human emancipation' (Smith, 2000: 11). Drawing from the process and praxis approaches, an explanation of the process through which curriculum is conceived and how that process is committed to the wellbeing of the society within which it is conceived, is central. This brings to the fore the notions of curriculum responsiveness and learning outcomes. In its reflexive nature, the praxis orientation to curriculum embodies commitment to human emancipation through clear 'intended learning outcomes' while leaving room for 'emergent learning outcomes' (Hussey \& Smith, 2003).

Scholars now emphasise that curriculum should be understood within a particular context (Moll, 2005; Smith, 2000). The different contexts are characterised by factors and pressures which impact on higher education. Moll (2005: 2) asserts that universities must respond to the expectations and pressures that are placed upon them. In the context of the so-called knowledge society, curriculum responsiveness may be understood as the requirements and efforts of education to address the knowledge and skills needs of society. As already noted, universities quite often present their curricula as products in order to attract students while also marketing their graduates as 'quality products' through the product approach. It is also noted that, within the praxis approach, curriculum is conceived as a commitment to human emancipation. From this view, curriculum is explored in terms of its relevance. Moll (2005) identifies four senses of curriculum responsiveness. These senses are briefly explained below: 
- Economic responsiveness: the curriculum should be 'responsive to the prevailing labour market by incorporating the necessary high levels of qualifications, knowledge and skills demanded by modern diversified economy (Moll, 2005: 5).

- Cultural responsiveness: the curriculum should be 'responsive to the cultural diversity of students and society by incorporating multiple cultural reference points that acknowledge diversity and constitute various alternative pathways for students (Moll, 2005: 6).

- Disciplinary responsiveness: the curriculum should be responsive to the nature of its underlying knowledge discipline by ensuring a close coupling between the way in which knowledge is produced and the way students are educated and trained in the discipline area (Moll, 2005: 8).

- $\quad$ Educational responsiveness: the curriculum should be designed in such a way that it ensures 'the maximisation of learning opportunities' (Moll, 2005: 9) of students through sensitive and productive teaching methods.

Given the country's history, Moll (2005: 10) indicates that curriculum responsiveness in South Africa has prominently featured in post-apartheid policies and debates related to Further Education Training (FET) provision and higher education transformation. This article will not belabour the point by further elaborating on the significance of these really critical issues in South Africa in a general way. Instead, the article identifies the relevant forms of curriculum responsiveness that are manifest in the lexicography at Rhodes.

\section{LEXICOGRAPHY AS A DISCIPLINE}

Conceptions of disciplines and knowledge within them affect the teaching and learning of certain fields of study (Neumann, Parry \& Becher, 2002; Parker, 2002; Toohey, 1999). Neumann et al. (2002) discuss disciplines according to their epistemological characteristics, i.e. the nature of their knowledge. This results in an oversimplified distinction between hard pure and soft pure knowledge, between which lie the applied forms, i.e. hard applied knowledge and soft applied knowledge. Hard pure knowledge is described as typically 'having a cumulative, atomistic structure, concerned with universals, simplification and a quantitative emphasis' (Neumann et al., 2002: 406). On the contrary, soft pure knowledge is 'reiterative, holistic, concerned with particulars and having a qualitative bias' (Neumann et al., 2002: 406). The applied knowledge communities then apply theoretical and methodological procedures of the pure disciplines in their teaching, research and practices.

Parker (2002) also presents a debate around the conception of 'subjects' and 'disciplines' in relation to higher education teaching and research, beliefs and confusion associated with these notions. The general feeling, according to Parker's (2002) exposition, has been that subjects are oriented towards the attainment of quantifiable skills and competencies while disciplines are associated with academic professions. 
Within the framework formulated by Neumann et al. (2002), lexicography may be located in the category of disciplines that can be described as soft applied knowledge. For a long time, it was regarded as part of linguistics (Landau, 1984; Atkins \& Rundell, 2008; Béjoint, 2010), which Neumann et al. (2002: 409) identify as constituted by soft pure knowledge that is also becoming hard pure knowledge. Primarily concerned with the production of dictionaries, lexicography was regarded as an 'art and craft' (Landau, 1984) which utilised linguistic data and theories (Zgusta, 1971; Atkins \& Rundell, 2008). Often, it has been explicitly identified as an example of so-called 'applied linguistics' (cf. Wiegand, 1984: 13). Accordingly, lexicography, developing within the framework of linguistics, consisted of applied soft knowledge. Within this frame, it was taught as a subject (cf. Parker, 2002) focusing on simple and quantifiable skills, e.g. how to collect material, how to select dictionary entries and how to define lexical items included in a dictionary (cf. Landau, 1984). It is not surprising that the first major lexicography text was entitled A Manual of Lexicography (Zgusta, 1971), i.e. suggesting that it was meant to provide guidance to lexicographers in carrying out their practical tasks. However, in 1983, John Sinclair regretted the view of lexicography as 'a group of specialized skills' (Sinclair, 1984: 3). The changes in the epistemological character of linguistics (Neumann et al., 2002) obtained from the emergence of computational linguistics were also incorporated into dictionary making, turning the underlying knowledge in the teaching of lexicography into applied hard knowledge. Nevertheless, as part of linguistics, lexicography would remain a subject, not a discipline. It would continue to be regarded as a linguistic practice (Zgusta, 1971: 17).

Changes began in the late 1970s and intensified in the early 1980s. Sinclair (1983: 3) modestly motivated for lexicography to be regarded as 'an academic subject' while Wiegand (1984: 13) argued strongly that lexicography was never 'a branch of the socalled applied linguistics'. Subsequently, the disciplinary status of lexicography was affirmed through an argument that identifies dictionaries as its subject matter, suggesting that lexicography has its own theory and methodologies over and above those of linguistics (Wiegand, 1983; Tarp, 2000; 2008; 2010). Yet other scholars opposed the disciplinary status of lexicography and its theoretical independence from linguistics (Atkins \& Rundell, 2008; Béjoint, 2010). Béjoint (2010), for example, argues:

The chapter on the theory of lexicography will be as short as a chapter on snakes in Ireland. I do not simply believe that there exists a theory of lexicography, and I very much doubt that there can be one. Those who have proposed a general theory of lexicography have not been found convincing by the community, and for good reasons. A theory is a system of ideas put forward to explain phenomena that are otherwise unexplainable. A science has a theory, a craft does not. All natural phenomena need a theory, but how can there be a theory of production of artefacts?

The stance adopted by such scholars indicates that the conceptualisation of lexicography remains a highly contested issue. Bergenholtz, Nielsen and Tarp (2009) aptly captured this situation by entitling their edited collection of papers dealing with lexicographic matters Lexicography at Crossroads. There have been both gradual and drastic changes 
in dictionary media (e.g. printed paper dictionaries versus electronic dictionaries), dictionary structure (e.g. alphabetic dictionaries and thematic dictionaries) and dictionary functions. Therefore, while it is remarkable that the $22^{\text {nd }}$ volume of Lexikos contains three articles (cf. Bergenholtz, 2012; Bergenholtz \& Gouws, 2012; Gouws, 2012) that address questions that 'can be regarded as ... the most unlikely and even most inappropriate ... to be put to the readers of a journal that is focusing exclusively on lexicographic matters' (Gouws, 2012: 217-218), redefining the core of lexicography remains a worthwhile intellectual undertaking. The questions addressed are:

- What is a dictionary? (Bergenholtz, 2012)

- What is lexicography? (Bergenholtz \& Gouws, 2012)

- Who can really be called a lexicographer? (Gouws, 2012).

The currency of these questions subsists in the fact that 'although the range of answers ... will have a lot in common there will also be some differences' which 'may lead to interesting discussions' (Gouws, 2012: 217-218). A Namibian survey reported in Beyer and Faul (2010) clearly illustrates this. Accordingly, Bergenholtz (2012) recommends definitions of dictionary which encapsulate different dictionary types, published in different media and serving diverse purposes. Bergenholtz and Gouws (2012) define lexicography in a way that takes into account both practical and theoretical lexicography while Gouws (2012) considers the relevance of the extent of participation in both practical and theoretical lexicography in order to answer the question 'Who can really be called a lexicographer'. Such nuanced interrogations have implications for lexicographic pedagogy.

The teaching of lexicography is now established in South Africa and other African countries such as Zimbabwe and Gabon. Several South African institutions such as Stellenbosch University, the University of Pretoria, Nelson Mandela Metropolitan University and Rhodes University offer lexicography modules and programmes. The 'importance and value of formal academic training for prospective lexicographers may never be underestimated' (Gouws, 2001: 61). However, Gouws (2001) reports that short courses have been useful for lexicographers who took up lexicographic responsibilities within the NLUs. Lexicographic pedagogy is not necessary for aspiring lexicographers only. Some school curricula recognise dictionary use as a skill that should be consciously developed (cf. ZIMSEC, 2008-2012: 13). Despite this, Taljard, Prinsloo and Fricke (2011: 107) observe that '[a]lthough reference is made to dictionary use in the [South African] school curricula', it 'seems to be a peripheral activity' (cf. Van der Merwe, 2012; Nkomo, 2013: 173) with school learners demonstrating only rudimentary dictionary consultation skills. Studies on dictionary use 'highlight[s] the need for a dedicated training of learners and teachers in the use of dictionaries' (Taljard, Prinsloo \& Fricke, 2011: 107).

Accordingly, whether lexicography should be taught at schools and universities is no longer the question. The question, which is two-fold, should now investigate, firstly, the aspects of lexicography that should be taught and, secondly, how the relevant aspects should be taught. This is precisely what the present article seeks to achieve with regard to the teaching of lexicography at Rhodes University. However, it does not proclaim a 
ground-breaking impact as far as the first part of the question is concerned. Further to the pioneering works of Sinclair (1984) and Wiegand (1984), there is now a sizeable body of scholarship that deals with dictionary or lexicographical pedagogy. For example, Hartmann (2001) and Gouws (2001) identify themes such as dictionary typology, dictionary structure, dictionary user, user needs, user skills, dictionary functions, dictionary research, dictionary criticism, dictionary history, etc. as fundamental in lexicographical pedagogy. The main contribution of the article lies in its motivation of what is taught to students in a South African university as well as the manner in which the teaching is conceptualised and implemented.

\section{LEXICOGRAPHY CURRICULA AT RHODES}

\section{Theoretical Approach}

Bernstein's theory of the pedagogic device is used to outline how the knowledge that constitutes lexicography was converted into the lexicography curricula at Rhodes University. According to Singh (2002: 572), the pedagogic device is a model for analysing the processes by which discipline-specific or domain-specific expert knowledge is converted or pedagogised to constitute school knowledge (classroom curricula, teacher-student talk, online learning)'. Its three main fields, namely production, recontextualisation and reproduction, imply that curriculum development constitutes the recontextualisation of the knowledge produced by higher education and research institutions to facilitate teaching. Teaching is seen as the reproduction of knowledge (Singh, 2002). The idea is that not every bit of knowledge in a particular field should always form part of the curriculum. Rather, the curriculum content culminates from a careful selection and arrangement of disciplinary elements into a coherent structure complemented by appropriate teaching methods. That way, it becomes possible to develop a curriculum that is relevant and responsive to particular needs.

\section{Background to the Teaching of Lexicography at Rhodes}

Lexicography was first introduced as an Honours module in the African Language Studies of the School of Language at Rhodes in 2010. The teaching of the module was outsourced as none of the then available staff members could teach it. Yet the introduction of lexicography was long overdue considering the practical lexicographic work close by at the Dictionary of South African English (DSAE) and at the IsiXhosa National Lexicography Unit (XNLU) at Fort Hare. Stellenbosch University and the University of Pretoria had already offered lexicography from Honours up to $\mathrm{PhD}$ for about 10 years. In a general way, the introduction of lexicography courses and programmes was a response to the need for academic guidance in the establishment and institutionalisation of the NLUs, as well as the activities of the NLUs in executing their mandate of producing dictionaries, which were identified as a necessary activity in the implementation process of the country's multilingual policy (Alberts, 2011; Gouws, 2003; Madiba \& Nkomo, 2010; Nkomo \& Wababa, 2013). However, the form and extent of such curriculum responsiveness can be better understood through a closer look at how the 
courses were designed and how teaching and learning is being conducted through the implementation of curricula plans. The next section discusses the development of the lexicography Honours module between 2011 and 2013.

\section{Lessons from the 2010 Module}

The point of departure in developing the Honours module in 2011 was an evaluation of the outsourced 2010 module. The evaluation relied on the module documents, which were supplied by the Head of the Department, and included the course programme (the course was presented as a one-week block course), assignments, the examination question paper and completed student feedback questionnaires. This article shall not enumerate the details in the mentioned documents. Suffice it to say that, despite good quality content, one week meant that students were bombarded with too much content over a very short learning period. At that time, the Honours students were introduced to lexicography for the first time through that module. Unsurprisingly, the time factor featured prominently as a constraint in the student feedback questionnaires. The fact that students did not have any background of lexicographic matters seems to have made matters worse. In the student feedback questionnaire, one student expressed concern that 'there are times when [the lecturers] would make this (sic) as if we are already lexicographers'.

Accordingly, the major decision taken was to teach the module over at least a term. That way, students would be introduced to different aspects of lexicography gradually. The long-term solution, though, would be to introduce certain aspects of lexicography at the undergraduate level, a suggestion that was made by some 2010 students in the feedback questionnaires.

\section{The Development of the Honours Lexicography Module (2012-2013)}

At the time of finalising this article, the author has been teaching lexicography at Honours level for three years (2011-2013). Besides the lessons drawn from the 2010 module, curriculum work in 2011 was also based on personal experience as a former lexicography student from Honours up to $\mathrm{PhD}$ level, as an academic and a practising lexicographer. The author was already aware of the general consensus regarding the central topics and broad aims in lexicography curricula despite some contestations highlighted earlier on. Since then, there has been constant dialogue with some NLUs, especially the DSAE and the XNLU regarding the issues in practical lexicography and the needs of these units. Gouws (2001: 58) sums them up as follows:

Lexicographic training is needed and should be directed at potential lexicographers, language teachers and dictionary users. The trainees should be equipped with the necessary knowledge to compile dictionaries, use dictionaries and understand dictionaries.

However, the general purpose and learning outcomes of the course should also be carefully considered according to the context within which the curriculum is conceived 
and the level of learning. A careful choice of topics should be considered taking cognisance of the desired goals in a particular context and in view of the students' needs. In South Africa, the following are considered to be particularly critical:

- developing a dictionary-using culture;

- developing dictionary-using skills;

- developing practical skills for prospective lexicographers.

The students are regarded as potential users of dictionaries in South Africa or prospective South African lexicographers and language teachers. The goals of addressing their needs are captured in the following excerpt from the overview section of 2013 Honours lexicography module document:

The broad aim of this course is to introduce and guide language students within the lexicography discipline which occupies a pivotal position in the history, status, use, development and future of languages. Students will be guided through an academic engagement with lexicography in relation to practice in but not limited to African languages of South Africa.

At least two sets of practical skills should be attained at the end of the course. Firstly, it is envisaged that students will acquire skills required of a practical lexicographer (steps, methodologies and principles of dictionary compilation). On the other end of the scale, students are also expected to develop awareness and skills of a competent user of lexicographical products of different types. ... With theoretical grounding that will be provided in the course ... students are expected to develop critical perspectives towards lexicography as it applies to the intellectualisation of languages. This should ultimately enable students to distinguish between good and bad lexicographic practice and, subsequently, good and bad lexicographic products.

Accordingly, the specific learning outcomes of the Honours module have not changed much between 2011 and 2013, as they have remained relevant to the South African context. Rather, what have changed are the teaching methods that are being deployed to achieve the learning outcomes. By the end of the Honours module, students are expected to:

- Demonstrate a comprehensive understanding of the purpose and relevance of lexicography in language learning, language practice and language development;

- Demonstrate an understanding of current theories and methodologies in lexicographic practice;

- Demonstrate sophisticated reference skills of effective users of lexicographic products of diverse types;

- Demonstrate critical skills of evaluating lexicographic products using the relevant theoretical principles; 
- Apply lexicographic theories to practical lexicography;

- Demonstrate comprehensive knowledge of South African lexicography and lexicography in other countries in Africa and Europe.

The above outcomes may be criticised for not fulfilling the nuanced requirements of the Outcome Based Education (OBE) which have been considered both useful and problematic (Hussey \& Smith, 2002; 2003). The uses of learning outcomes lie in them being 'practical tools both in the activity of teaching and learning in designing courses of study' (Hussey \& Smith, 2003: 367). In teaching and learning, learning outcomes provide for what Biggs (1996) calls constructive alignment. The notion of constructive alignment can be understood as follows:

Good teachers are expected to be clear about what they want students to learn and what students should have to do in order to demonstrate that they have learned at the appropriate level; they should know and enact ways of getting their students to learn effectively at the desired cognitive level; to be more student-centred in their teaching activities, and more authentic in their assessments. (Biggs, 1996: 361)

Echoing similar sentiments, Hussey and Smith (2003: 361) argue that '[e]ffective alignment ensures consistency throughout, maximising transparency of intentions, selecting, and using teaching and learning methods likely to achieve the intentions and assessment tasks clearly reflecting those intentions' However, they also note that, in curriculum design, the specificity of learning outcomes should not be the sole focus and that the learning outcomes should be responsive, realistic and flexible. They argue that 'it is neither practical nor useful to try to specify learning outcomes with the kind of precision that is being sought', and that learning outcomes 'will remain ambiguous whatever descriptors are used' (Hussey \& Smith, 2002: 225). An example of 'understanding', which features prominently in the learning outcomes of the Honours module presented above is given as an ambiguous descriptor since 'understanding can be profound or superficial, sophisticated or naïve' (Hussey \& Smith, 2002: 225). Consequently, learning outcomes have met fierce criticism, with Knight (2001: 373) arguing that learning is complex and thus not 'easily reducible to precise statements predicting what the outcomes will be'. With the Honours module being offered to postgraduate students, the concern has transcended the desire to achieve a clear and accurate formulation of learning outcomes and focused on ensuring that the curriculum has the necessary elements to facilitate complex learning. This is important to ensure competent dictionary users, skilled lexicographers and knowledgeable and critical teachers who should be able to impart dictionary skills to their learners.

The organisation of content, the choice of teaching methods and the design of learning activities have also been done with a view to facilitating learning that is relevant to the South African context. The module is structured into seven sessions of two and a half hours (with a break in between) and it identifies the following as the key topics:

- The historical development of lexicography as a discipline; 
- $\quad$ Lexicographic theory;

- Dictionary typology;

- Dictionary structure;

- $\quad$ Practical lexicography;

- Lexicography of African languages.

These topics can be regarded as the elements that can collectively contribute to the achievement of the three broad objectives of the course. The objectives of each session are clearly identified in the course document. For example, by the end of the session dealing with the lexicography of African languages, students should be able to:

- Understand the role and impact of the activities of missionaries and colonial administrators in the development of African language dictionaries;

- Relate lexicography to language policies, language planning and language development in Africa;

- Identify linguistic challenges affecting lexicography in African languages;

- Identify the progress and prospects of lexicography in African languages;

- Account for the South African lexicographical situation as a case study;

- Compare South African lexicography with practice in other African countries as well as countries from other parts of the world.

Having clearly identified objectives for each session makes it easier to evaluate the effectiveness of each session and ultimately the entire module.

\section{Teaching and Learning Activities}

Besides listing the objectives of each session, the teaching and learning activities are also identified. For the same session dealing with the lexicography for African languages, the following brief is given in the course document:

Students will be advised to compile inventories of dictionaries in their languages before the session. Historical, typological, structural, functional and critical perspectives (Hartmann, 2001) will be adopted in the exploration of African language lexicography.

The main method of teaching in this session will be a lecture but students will be frequently asked to supply examples from dictionaries in their languages.

The teaching and learning activities are identified in relation to the subject matter of each session. For example, for the session dealing with lexicography in African languages, the lecture is identified as the most appropriate teaching method in that students are not expected to know the history and the other factors that have shaped lexicography in African languages. The delivery method thus becomes dominant. However, students are given the responsibility to do research about existing dictionaries in their own languages and assisted in locating these dictionaries within the established epochs in the 
development of African languages. This is meant to put them in a better position of understanding the key issues as they would come to the session already having ideas about the nature of the existing dictionaries in their own languages. The lecture and the ensuing discussion are meant to draw examples from the dictionaries that students have already identified in their own languages. An effort is thus made to respond to the different linguistic backgrounds of students by allowing them to study dictionaries in their own languages in comparison with those in other languages spoken by their peers. This, in terms of Moll (2005: 6), is the cultural responsiveness dimension of the lexicography Honours module under discussion.

In addition to the lecture method, student presentations are also central in the course. For example, for the session on theoretical lexicography, a student presentation preceded the lecture, with one student presenting his/her reaction on a half a page-long chapter in Béjoint (2010) dismissing the theory of lexicography. As short as this chapter is, it summarises some of the strong attitudes and positions on the topic. This becomes an effective introduction to different theories of lexicography and their relevance, asking whether the theory of lexicography is necessary before going on to explore a number of existing theories.

According to Tarp (2008: 1), theory and practice are closely interconnected in lexicography. Teaching and researching lexicography constitutes the theoretical dimension of the field, while dictionary making and dictionary use are practical. When students are taught about dictionary structure and dictionary functions, they acquire skills which improve their dictionary use. However, they do not acquire the practical skills of dictionary making. Accordingly, an educational excursion to the XNLU was introduced in 2012 and has become a major highlight of the course. It has provided students with exposure to the practical dictionary-making processes in a way that complements the theoretical sessions. While a guest lecture on practical lexicography was offered by a lexicographer from the DSAE in 2011, some students seemed to be lost as it focused on English dictionaries. The trip to the XNLU enabled students to understand the practical challenges and lexicographic procedures that apply to African languages.

\section{Lexicography at Undergraduate Level}

A few aspects of lexicography have been taught in the form of guest lectures by this author to second- and third-year students in the department since 2011, with emphasis being placed on the skills that students need in other courses such as translation. The positive reception of those lectures, coupled with Honours students' suggestions that they would have performed better had they possessed introductory background knowledge of lexicography, inspired the conceptualisation of an undergraduate lexicography module that has been taught to first-year students since 2012. This module, which is taught in isiXhosa, mainly focuses on developing dictionary skills and, unlike the Honours module, does not dwell on the dictionary-making processes and theoretical issues. It is mainly aimed at developing a dictionary culture among the students of isiXhosa, some of whom go on to be language teachers in the schools. Consistent with this broad aim, the undergraduate lectures are developed around the following specific issues: 
- the central role of the dictionary as part of linguistic, cultural and intellectual development of a community;

- the different kinds of information that can be obtained from dictionaries;

- the various structures and sub-structures of dictionaries which distinguish them from other texts and determine their consultation procedures;

- the various types of dictionaries and the motivation behind their classification;

- the functions of dictionaries in language learning, language studies and professional language practices such as translation and editing;

- $\quad$ the history and inventory of dictionaries in isiXhosa.

The undergraduate module is thus only an introduction to the Honours module as it also prepares students for further studies in the field, although not all of these students go on to do lexicography at the Honours level.

\section{Learning Materials}

One of the 2010 module documents that were reviewed in the process of developing the subsequent curricula was an information sheet that was distributed at the beginning of the course. The information sheet identified Gouws and Prinsloo (2005) as the prescribed course textbook. It also advised students to bring money for purchasing the book which was sold during the one-week block course. Gouws and Prinsloo (2005) is currently the most comprehensive and up-to-date text on South African lexicography. However, basing the entire Honours module on one text and selling it during the course implies that students could not prepare for lectures; there was thus no room for a 'deep learning approach' (Biggs, 1999). Besides this book, students had to rely on the notes that were provided by the lecturers. As a corrective procedure from 2011, the module document has included a reading list which comprises more texts and journal articles. The included books are available at the main library, the DSAE library, the lecturer's personal collection and online resources. A detailed course outline and a reading list are considered as resources that would enable a deep learning approach instead of a surface learning approach and a heavy reliance of students on the lecturer. In addition to those secondary sources, students are always encouraged to bring different dictionaries that they can access so that they become part of theoretical description that is provided by the module. Accordingly, the lecturer's role is seen as facilitating learning by providing theory and guidance to the relevant sources of knowledge about dictionaries, the practical tools that students are expected to be using on a regular basis.

\section{CONCLUSION}

The main purpose of this article was to reflect on curriculum issues with regard to the teaching of lexicography at Rhodes University. The importance of teaching lexicography has been underscored in the context of South Africa's multilingual language policy. It has been noted that dictionaries and dictionary making have an important role to play in the implementation of this policy. Language students need to be trained to become competent dictionary users, skilled lexicographers and teachers who can effectively teach their own 
learners about effective dictionary use. Teaching lexicography becomes a form of dictionary research.

Accordingly, the teaching of lexicography in South African institutions of higher education and even schools is relevant. However, since lexicography is now an established discipline with a wide range of issues constituting its knowledge base, it is vital that the relevant curricula are conceptualised with great care to achieve relevance. Not all lexicographic issues would be of relevance to the South African context and not all of them can be taught effectively within a short time frame. Thus, through the application of Bernstein's theory of 'pedagogic device', explained in Knight (2001), the relevant themes have to be selected, guided not only by the South African context but also the level of the students. Again, not only the understanding of lexicography as a discipline is sufficient. It is equally vital to address curriculum issues of a theoretical nature, such as curriculum orientations, curriculum outcomes and curriculum responsiveness. From 2011, the teaching of lexicography as an Honours module at Rhodes has made improvements on the 2010 module that was outsourced. It became apparent along the way, though, that an undergraduate module was needed to address the needs that students faced in their other modules in the department while providing them with the background that would make learning easier for them should they study lexicography at the Honours level.

\section{REFERENCES}

ALBERTS, M. 2011. National lexicography units: past, present, future. Lexikos, 21:23-52

ATKINS, SB \& M RUNDELL. 2008. The Oxford guide to practical lexicography. Oxford: Oxford University Press.

BÉJOINT, H. 2010. The lexicography of English. Oxford: Oxford University Press.

BERGENHOLTZ, H \& RH GOUWS. 2012. What is lexicography? Lexikos, 22:31-42.

BERGENHOLTZ, H, S NIELSEN \& S TARP. 2009. Lexicography at crossroads. Bern: Peter Lang.

BERGENHOLTZ, H. 2012. What is a dictionary? Lexikos, 22:20-30.

BEYER, H \& AK FAUL. 2010. Namibian university entrants' concepts of 'a dictionary'. Lexikos, 20:644-679.

BIGGS, J. 1996. Enhancing teaching through constructive alignment. Higher Education, 32:347-364.

BIGGS, J. 1999. What the student does: teaching for enhanced learning. Higher Education Research and Development, 18(1):57-75.

BOUGHEY, C. 2004. Higher education in South Africa: context, mission and legislation. In Gravett, S \& H Geyser (Eds), 2004:1-31. Teaching and learning in higher education. Pretoria: Van Schaik.

CROSS, M, R MUNGADI \& S ROUHANI. 2002. From policy to practice: curriculum reform in South African education. Comparative Education, 38(2):171-187. 
GOUWS, RH \& DJ PRINSLOO. 2005. Principles and practice of South African lexicography. Stellenbosch: Sun Press.

GOUWS, RH. 2001. Lexicographic training: approaches and topics. In Emejulu, JD (Ed), Éléments de lexicographie gabonaise. Tome I, pp. 58-94. New York: JimacsHillman.

GOUWS, RH. 2003. Towards the formulation of a theoretically motivated model for the National Lexicography Units in South Africa. In Hartmann, RRK (Ed), Lexicography: critical concepts, pp. 218-246. London: Routledge.

GOUWS, RH. 2005. Lexicography of Africa. In Brown, K (Ed), Encyclopedia of Language and Linguistics ( $2^{\text {nd }}$ ed.), pp. 95-101. Oxford: Elsevier.

GOUWS, RH. 2012. Who can really be called a lexicographer? Lexikos, 22:217-225.

HARTMANN, RRK. 2001. Teaching and researching lexicography. Harlow: Pearson Education.

HUSSEY, T \& P SMITH. 2002. The trouble with learning outcomes. Active learning in Higher Education, 3:220-233.

HUSSEY, T. \& P SMITH. 2003. The uses of learning outcomes. Teaching in Higher Education, 8(3):357-368.

Imaginative Curriculum Network. Contexts for curriculum design: Working with external pressures. LTSN Generic Centre.

KNIGHT, PT. 2001. Complexity and curriculum: a process approach to curriculum-making. Teaching in Higher Education, 6(3):369-381.

LANDAU, SI. 1984. Dictionaries. The art and craft of lexicography. Cambridge: Cambridge University Press.

MADIBA, M \& D NKOMO. 2010. The Tshivenda/English Thalusamaipfi Dictionary as a product of South African lexicographic processes. Lexikos, 20:307-325.

MOLL, I. 2005. Curriculum responsiveness: The anatomy of the concept [Online]. Available: http://www.saide.org.za/Resources/SearchOurDatabase/SearchResults/tabid/1488/mc 1/Details/id/37738/Default.aspx [2012, 12 December].

NEUMANN, R, S PARRY \& T BECHER. 2002. Teaching and learning in their disciplinary contexts: a conceptual analysis. Studies in Higher Education, 27(4):405-417.

NKOMO, D \& Z WABABA. 2013. IsiXhosa Lexicography: past, present and future. Lexikos, 23:348-370.

NKOMO, D. 2013. Towards internally-motivated English school dictionaries for Zimbabwe. In Botha, V, PA Mavoungou \& D Nkomo (Eds). 2013. Festschrift: Rufus H Gouws, pp. 165-187. Stellenbosch: SUN Press.

PARKER, J. 2002. A new disciplinarity: communities of knowledge, learning and practice. Teaching in Higher Education, 7(4):373-386.

RHODES UNIVERSITY. Rhodes university policy on curriculum development and review [Online]. Available: 
www.ru.ac.za/media/rhodesuniversity/content/institutionalplanning/documents/curri ulumdevelopment.pdf [2012, 12 December].

SINCLAIR, J. 1984. Lexicography as an academic subject. In Hartmann, RRK (Ed), LEX'eter '83 Proceedings. Papers from the International Conference on Lexicography at Exeter, 9-12 September 1983, pp. 3-12. Tübingen: Max Niemeyer.

SINGH, P. 2002. Pedagogising knowledge: Bernstein's Theory of the Pedagogic Device. British Journal of the Sociology of Education, 23(4):571-582.

SMITH, MK. 2000. Curriculum theory and practice. The Encyclopedia of Informal Education [Online]. Available: www.infed.org/biblio/b-curric.htm [2012, December 12].

TALJARD, E, DJ PRINSLOO \& I FRICKE. 2011. The use of LSP dictionaries in secondary schools - a South African case study. South African Journal of African Languages, 31(1):87-109.

TARP, S. 2000. Theoretical challenges to practical specialised lexicography. Lexikos, 10:189208.

TARP, S. 2008. Lexicography in the borderland between knowledge and non-knowledge: general lexicographical theory with particular focus on learner's lexicography. Tübingen: Max Niemeyer.

TARP, S. 2010. Reflections of the academic status of lexicography. Lexikos, 20:450-465.

TOOHEY, S. 1999. Designing courses for higher education. Maidenhead: Society for Research into Higher Education and Open University.

VAN DER MERWE, MF. 2012. A Study of the Use of the HAT Afrikaanse Skoolwoordeboek by Primary School Children. Lexikos, 22:352-366.

WIEGAND, HE. 1984. On the structure and contents of a general theory of lexicography. In Hartmann, RRK (Ed), LEX'eter '83 Proceedings. Papers from the International Conference on Lexicography at Exeter, 9-12 September 1983, pp. 13-30. Tübingen: Max Niemeyer.

ZGUSTA, L. 1971. A manual of lexicography. The Hague: Mouton.

ZIMSEC. 2008-2012. Zimbabwe General Certificate of Education (ZGCE) for examination in November 2008-2012 'O' Level Syllabus English Language (1122).

\section{BIOGRAPHICAL NOTE}

Dion Nkomo is a Senior Lecturer at the African Language Studies Section of the School of Languages, at Rhodes University. His teaching and research interests include language planning and policy, lexicography, translation, terminology and comparative Nguni studies. He has practiced as a language practitioner and lexicographer with the African Languages Lexical (ALLEX) Project at the University of Zimbabwe and the Multilingualism Education Project at the University of Cape Town. Email address: d.nkomo@ru.ac.za 